\title{
Changing the Conversation about Teacher Development - Is It, Truly, a "Mirage"? An Analytical Review of The Mirage: Confronting the Hard Truth about Our Quest for Teacher Development and a Practitioner's Perspective on Teacher Development
}

\author{
Dr. Gabriela E. Gui \\ Assistant Professor, Grand Valley State University \\ College of Education \\ Educational Leadership and Counseling Unit \\ 401 Fulton Street W. \\ Grand Rapids, MI, 49504 \\ USA
}

\begin{abstract}
TNTP's The Mirage: Confronting the Hard Truth About Our Quest for Teacher Development(TNTP, 2015) was a study released in August 2015.Usingdatacollected from three large, geographically diverse public schools and one mid-sized charter network, the study argues that, despite of tremendous investment of financial resources, time, and good will in teacher development, there are very modest returns on this investment. The authors contend that we do not know how to improve teachers at scale, making the goal of effective professional development a mirage. Recommendations suggested by the authors include redefining teacher development; reevaluatingtheeffectiveness of current supports and programs; and reinventing the way effective teaching is supported at scale. The study's strength is in the rich descriptive information provided. However, the authors make poor analytic choices, rendering somewhat inaccurate conclusions, and thus limiting the study's usefulness.
\end{abstract}

Keywords: professional development, developing teachers, teacher effectiveness, improving teacher practice

\section{Introduction and Framing}

Numerous studies in the past decades have established a direct correlation between student learning and the instructional effectiveness of teachers (Darling-Hammond\& Youngs, 2002; Goddard, Hoy, \& Hoy, 2000; Hill, Rowan, $\&$ Ball, 2005). One great theory of action in education is that better teachers and teaching lead to improved student learning which, in turn, will maximize student success in college and careers.

The need to secure high-quality, knowledgeable teachers - masters of core instructional skills and of creating engaging and rigorous environments where all students learn - is critical for all schools. This is especially urgent for fragile contexts - historically underachieving, high-povertyschools, with educators teaching children with severe academic and emotional needs in large urban areas, orin remote geographical environments, where effective teaching becomes an issue of equity and access to educational opportunities.

The topic of building instructional capacity in our educators has been morerelevant and critical for educators around the world since the early 2000's. In the United States of America, for example, increased accountability stemmed from the provisions of the No Child Left Behind Act of 2001 (NCLB, 2001) that require states to describe and demonstrate how they close the achievement gap and how students, including those at-risk, achieve academic proficiency.

In addition, since 2009, over two-thirds of states have made significant changes to how teachers are developed professionally and evaluated. For most states, thisshift was motivated by incentives offered by federal programs such as Race to the Top, No Child Left Behind waivers, and the Teacher Incentive Fund. State applications for supplemental funding could earn additional credit for upgrading teacher evaluation systems and, implicitly, supporting teachers' growth in more targeted ways (Bornfreund, 2013). The pressure was on.Teacher evaluations had to be conductedannually and they had to include student achievement or growth measures as part of the evaluation system. The inclusion of student academic achievement or growth measures was one of the most dramatic and controversial changes instituted in the past decade or so.Although the connection between the quality of teaching and student learningcould be considered axiomatic, now, all of a sudden, teacher performance started being judged for its impact on student learning. 
Consequently, school districts felt compelled to increase the premium on supporting teachers in improving their practice in new, more systematic ways. No wonder, then, that The New Teacher Project (TNTP)has placed its core focus in helping school districts build and support effective teams of talented educators.

Who is TNTP? According to information on their website, the national nonprofit organizationwas founded in 1997 by a group of teachers. When they started out, their core initiative was the Teaching Fellows, a program that prepared individuals possessing great content knowledge to teach in high-need schools and subjects. In the early years, TNTP established partnerships with large urban districts such as New York City, Washington, D.C., Baltimore, and New Orleans.Later on, they prioritized writing policy reports and providing hands-on consulting to more than 200public school districts, charter school networks, and state departments of education.

I had the privilege to collaborate with them directly on several significant initiativesduring 2015-2017, while I worked as a Principal Manager and Executive Director of Talent at the Education Achievement Authority, supporting the lowest performing schools in Detroit. By then, TNTP had established its reputation as a serious player in the educational world and had published some influential education policy studies, including The Widget Effect (2009) and The Irreplaceables (2012). Iam familiar with their approaches to build teacher capacity and effectiveness; I witnessed first-hand their expertise in analyzing, advising, and offering pragmatic support in creating systems that promote excellence in teaching and learning; and I benefited professionally and personally from our collaboration. I have the deepest respect for their work. Moreover, I made many friends in the process of working together. And yet, as a practitioner of 30 years in the field of education (in traditional public and charter school districts) and as a researcher,I believe some aspects of the methodology used in this study and parts of findings, conclusions, and recommendations are problematic.In this analytical review I intend to show why.

\section{Purpose of Review}

Why are teachers "marching in place" (p. 13) in terms of their professional growth? How helpful is the current investment in their development? Do we even know what works? How knowledgeable and skilled are school and district staffs responsible to support teachers improve their practice? The TNTP studyargues that we don't know how to improve teachers at scale, and the goal of effective teacher development remains a mirage, distant and unattainable.Was this true in 2015, when the study was released? Is it true now, more than 5 years after the findings?

After TNTP's The Mirage: Confronting the Hard Truth About Our Quest for Teacher Development(TNTP, 2015) was published in 2015, the reportwas examined and talked about at some extent in blogs, a few formal reviews, and brief articles. A comprehensive reviewwas conducted at the request of the National Education Policy Center at the University of Colorado Boulder's School of Education. Heather C. Hill, the Jerome T. Murphy Professor in Education at the Harvard Graduate School of Education, was the author of this review and she found merits in the descriptive sections of the study, while advising against using it for policy making due to some key weaknesses in the study.

However, none of the reviews, analyses, or interpretations were done from a practitioner's perspective - and this is what I will attempt to do with this article. How might teachers, school and district leaders perceive the information shared and analyzed in The Mirage? What could they think about the findings and recommendations?

Benefits of this "new look" at the study include dispelling the myth that effective teacher development is unattainable because we don't know yet what works; providing arguments that we can improve teacher practicewithout resorting to the more radical recommendations made by TNTP (such as reconstructing teachers' jobs); and creatinga new sense of urgency in investing resources in whathelps teachers master core instructional skills at scale and in a systematic way.Figuring out what it takes to help teachers improve is a big task.The onusis on all of us.

\section{Research Findings-at-a-Glance}

The study The Mirage: Confronting the Hard Truth About Our Quest for Teacher Development(TNTP, 2015) makes several important arguments: the investments districts make in teacher development are much larger than what most people think - and yet, most teachers appear to be "marching in place" (p. 13) in terms of improving their performance; there is a pattern for teacher growth, with more substantial improvements within the first few years of teaching, after which a plateau follows before teachers could master core teaching practices; teachers who improve do not spend more time in PD than the non-improvers; self-reported attributes of being reflective and having a growth mind-set do not make a difference in terms of improving practice; the usefulness (or lack thereof) of professional development is perceived similarly by improvers and non-improvers; a closer alignment between teachers' perception of their own teaching effectiveness and their formal evaluations and openness to feedback seem to correlate withimproved practice. 
In addition, the study claims that, in general, school districts are not doing a good job at helping teachers identify their areas of improvement, but rather function in a disjointed and impersonal way (p. 28), in spite of being well-intended.

One exception to the general argument that most teacher development is ineffective seems to be the mid-sized charter school network in the study. TNTP claims that, while the problem of teacher development was not solved entirely by the charter management organization $(\mathrm{CMO})$, its approach to teacher development led to more professional growth over time as compared to that of teachers in traditional public schools.

\section{Review of Research Scope and Methodology;Perspectives}

TNTP uses original data collected from three large, geographically diverse traditional publicschool districts and one mid-size public charter network. In total, these districts employed over 20,000 teachers; had approximately 400,000 students enrolled; and had annual operating budges ranging from $\$ 800$ million to $\$ 3$ billion.

More than 10,000 teachers and 560 school leaders were surveyed.Interviews were conducted with 127 district staff members and school leaders. Focus group discussions were held with teachers. The researchers also conducted analyses ofprofessional development offerings, session attendance, 2 to 4 years of teacher effectiveness evaluation data, district-provided instructional coaching data, and budgets.

In spite of what appears to be an extensive reach, the study examined just three traditional school districts and one charter school network, all anonymous.This seems like a small drop in the sea of k-12 institutions in the United States, with over 15,000 public and private school districts. Samples were also not randomized. Can generalizations be made under these circumstances?

Consequently, this study is both comprehensive and limited: comprehensive because it is a massive undertaking to better understand the professional growth of teachers, yet limited due to the fact that it only investigates a slice of teachers in a slice of classrooms in a very small number of districts that were not chosen randomly.

Researchers identified teachers withsubstantially improved performance;looked for common experiences, mindsets, and the work environments of improvers; and then compared those to other teachers who did not improve. This methodology is different from most research on professional development (PD)that looks at a particular development initiative or strategy that was implemented, and then tracks results.

In terms of professional development activities, researchers from TNTP took into consideration a variety of types and forms, including: traditional, one-time PD; extended PD initiatives;peer classroom observations; administrator observations; teachers' own (independent) efforts; completing university coursework; formal and informal peer collaboration; receiving direct coaching; mentoring; spending time with a formal evaluator; formal and informal feedback; strategies modeling and practice; and teacher preparation. In spite of this extensive inclusion of developmental experiences, the inability of the TNTP researchers to measure the quality of professional development experiences - an indicator that is most pertinent to the growth of teachers - weakens the study's analytical evaluation component.

Feedback on these experiences from teachers and principals was also collected, along with information about individual teacher mindsets, openness to feedback, self-assessment of teaching effectiveness; and reactions to developmental activities. School leader reactions and the collective responses from teachers working in the same school were also tracked.

From the practitioner's perspective, TNTP's study is most powerful when describing data collected through interviews and surveys. Teachers' beliefs about their teaching effectiveness, for example, rings true to anyone who has served as principal or central office administrator. Yes, there are teachers who are reflective, open to feedback, and good evaluators of own strengths and areas of improvement. However, in general, a much larger percentage of teachers doubt that they have serious weaknesses in their teaching practice, in spite of ratings from their supervisors showing otherwise and dismal student achievement results. Poor self-assessment of teaching effectiveness, lack of a growth mind-set, and lack of a common understanding of what "good teaching" means could be obstacles to their improvement.

Another aspect of the study that resonates with practitioners in the education field is the data collection strategy through teacher interviews and surveys, accompanied by thorough analyses.

Especially powerful is the authors' descriptive information related to both the sad reality that professional development in our public schools does not necessarily lead to improvements in teaching and learning, and that of the lack of coordination and targeted efforts on the part of professional development designers/providers. 
On the other hand, researchers claim that they calculatedteacher growth using multiple measures: summative teacher evaluation ratings, classroom observation scores, and value-added scores. This does not technically qualify as multiple measures: summative evaluation scores are calculated based on indicators including, in substantial percentages, the results of classroom observations and the measures of student achievement. For most school districts, these two categories constitute more than $75 \%$ of a summative evaluation. Currently, state laws require between $25 \%-40 \%$ of half of teacher and administrator evaluations be based on student growth and assessment data, with half of the growth component of evaluations comprised of state assessment data for tested grades and subjects.

Another issue with the calculation of teacher growth used by TNTP is the unreliability of evaluation data. Let's take the student achievement (proficiency)and growth data first. Student achievement data comes from what is called common assessments - which are described in literatureas assessments "administered in a routine, consistent manner by a state, district, or school to measure students' academic achievement" (Hamilton\& al., 2009). These could include high-stakes state accountability/standardized tests (annual or not),such as those required byEvery Student Succeeds Act of 2015 (ESSA, 2015); tests producedcommercially; end-of-course assessments designed by districts or schools; etc. Those who have worked inthe education field and educational researchers alike agree that measuring student proficiency is a very controversial issue for national, state, and local school boards, due to questionable validity. Teachers across the country have objected to using proficiency marks as indicators of individual teacher performance. Among the reasons why proficiency targets are problematic: they are not accurate in reflecting teachers' impact on student learning; it might not be realistic to expect that all students reach proficiency at the same time, considering various entry levels; and they might overlook students who perform at the highest and lowest levels. In addition, Heather Hill (Hill, 2015) points out that educational research has confirmed that "teacher value-added rankings are very often inconsistent between years, between tests administered in the same year, or even inconsistent between sub-sections of the same test" (p. 5).

Approaches to measuring student growth include Student Growth Percentiles (SGPs), that measure the learning of individual students over one or more years, and Student Learning Objectives (SLOs), that are long-term, measurable academic goals that teachers set at the beginning of a school year for students. These, too, are problematic. Drawbacks include: challenges related to setting realistic, but rigorous targets for all students; lack of quality of pre- and post-test designs; more complex and often subjective scoring; and ensuring comparability across teachers (Bennett, 2020).

An even bigger issue is the lack of reliability and validity of formal classroom observation results. Researchers and practitioners agree that classroom observations are most useful when they are done frequently; used as a formative process; are followed by timely and effective feedback;and when observers are normed - with other words, when highquality observation protocols are being used. This is not the case for formal classroom observations. The required number of formal observations per year ranges from 2 to 4 , andthis is too small of a sample to draw conclusions about the teacher's overall effectiveness. The formal evaluations are usually high-stakes, having consequences on teacher's retention, promotion, or compensation. Often times, teachers are so stressed out by these observations that their performance is negatively influenced. The quality of feedback also differs from observer to observer, school to school, and district to district. Typology of unhelpful feedback includes feedback that is late, unimportant, overwhelming, too vague/broad, condescending, and uninformed. And lastly, norming observers is- well, not the norm in all schools.

Beginning with 2016, after the publication of The Mirage (TNTP, 2015), education policy-makers, researchers, board members, district/school administrators, and teachers started talking more loudly about how formal classroom observations are not a good way to evaluate teacher effectiveness. This was more than a year after Sutton Trust published its studyWhat Makes Great Teaching(Coe etal., 2014) in October of 2014, in which the accuracy of classroom observations was described as barely better than lucky guesses.

Currently available measures can give useful information, but there is a lot of noise around a weak signal, so we must be careful not to over-interpret. If we were to use the best classroom observation ratings, for example, to identify teachers as "above" or "below" average and compare this to their impact on student learning, we would get it right about $60 \%$ of the time, compared with the $50 \%$ we would get by just tossing a coin. Therefore, these judgements need to be used with considerable caution. (p. 3)

Finally, although the school districts in the study were not identified, any educator worth her salt would be able to infer, by looking at the demographics provided, that the schools under study were from high-poverty, urban settings. Since these tend to have, on average, more inexperienced teachers and higher rates of teacher attrition, a question remains if teacher turnover was taken into consideration for this research. 
Due to the considerations presented, myconclusion is that the study's methods and evidence cannot support its strong conclusions in an undisputable way.

\section{Review of Findings and Perspectives}

The major finding in TNTP's study is that, in spite of considerable resourcesinvested in teacher development and the impressive commitment to develop teachers' instructional capacity, reaching the goal of having an effective teacher in each one of our classrooms remains a mirage. The authors are"confronting the hard truth" (p. 2) that we do not know what works in growing teachers' instructional practice at scale, and that "the evidence base for what actually helps teachers improve is very thin" (p. 2).

In the 2015 blog The Five Stages of the Mirage(Belcher, 2015), Karolyn Belcher, a founding member and then president of TNTP, contends that digesting the findings of the study was a sobering process for her, similar to the five stages of grieving.

So, coming to terms with these findings has been, in some ways, tough for me. Processing The Mirage has been a little like the five stages of grief: first, there was denial (no-this methodology must be wrong!); then anger (how dare you say our work isn't helpful? How is this report helpful?); followed by depression (it's all hopeless; should we just scrap all of our work?); bargaining (maybe if we just tried this other professional development approach, in this improved way?) and finally, acceptance. This isn't what we wanted to hear, but we can learn from it-and we might need to hear it to really make a difference. (p. 2)

As a former teacher, principal, and principal manager, I can see how someone who cares deeply about education, yet has not been directly involved in teacher development, could feel this way. Nonetheless, such an emotional response from an experienced educator is somewhat surprising. We are far from being clueless with respect to developing teachers. The evidence is out there. The ones that come to mind immediately, similar in demographics to schools in this study, include many of the 55 public charter schools Uncommon Schools manage(North Star Academy Charter School being the "star"); most of Achievement First and National Heritage Academies;schools in the KIPP network; Oakland International High School; Artesia High School in Los Angeles; schools belonging to the Denver School of Science and Technology (DSST) network, etc. I experienced evidenced success with teacher development first hand at Univeristy Prep Science and Math High School in Detroit, during 2010-2014. Pockets of excellence in teacher development also exist within New York, Chicago, San Diego, and many other publicschool systems.

One concrete example is actually included in TNTP's study: the schools in the mid-sized charter management organization (CMO) operating in several cities. The authors of The Mirage(TNTP, 2015) assert that "[t]his CMO takes a markedly different approach to teacher improvement than the other districts we studied"(p. 30) and, later, "their results seem promising, and point to several strategies other districts might consider as they reassess their efforts to help teachers improve" (p.30).

Wouldn't this warrant, then, a closer look at the quality of professional development offered by the CMO in comparison to the two traditional public school districts? What is the CMO doing well, with respect to teacher development, that could be transferable to other school systems?

While the authors of the study contend that, "meaningful improvement in the $\mathrm{CMO}$ - while more frequent than in the other districts we studied - is just as much of an individualized process, lacking in any particular pattern" (p. 30), they also acknowledge that there are some differences at the institutional level. Among the key differences for the midsized charter network, most notable are: a clearer division of work - specifically, who is responsible for teacher development; a culture of continuous learning and high expectations; prioritizing regular classroom observations;providing meaningful feedback with consistency and opportunities to practice; a strategic approach to teacher development, focusing on individualized support; and increased accountability at all levels.

Research on, and evidence from the field for leading professional development that works, agree that these, along with other several strategies, are essential in creating a systematized approach to developing teacher's instructional capacity. More on this in the Review of Recommendations and Perspectives portion of my article.

One of the study's findings that I find most intriguing is the school districts' extensive financial and time investment in teacher development. The study's authors claim that these school systems spend around \$18,000 (approximately 6-9\% of their annual operating budgets) and 150 hours (approximately $10 \%$ of a school year) per teacher, peryear, dedicated to instructional growth efforts (p. 8). These numbers seem very high, even if the dollar amount considers both direct and indirect costs. 
TNTP factors into its "middle range" calculations the costs associated with the time spent on teacher support by school and central office personnel, such as principals and assistant principals, mentors, coaches, instructional deans, curriculum specialists, PD directors, professional learning community(PLC) leaders, etc. This cost for the salaries and benefits of these individuals is, by far, the largest financial investment made by the school districts in the study. Other costs are associated with "materials and supplies for professional development,contracts with vendors, the cost of teacher time spent onprofessional development days, and formal collaborationand stipends for development activities" (p. 10).

In addition, the researchers also took into consideration the costs for other initiatives related to teachers' improved practices: development and implementation of evaluation systems, additional time teachers might spend participating in coaching and peer observations; increases in teachers' salaries and stipends awarded at the completion of a degree or training; and other costs indirectly associated with supporting teachers at school or district levels. This calculation method is quite unique: most research studies on this topic omit some of these costs.

From the practitioner's perspective, it is doubtful that all staff delegated to support teachers in improving their practice can dedicate $100 \%$ of their time to those efforts. Years of experience working in schools and at the central office levels indicate that the dynamics of a school and competing priorities get in the way of the best laid plans for maximizing teacher development consistently and long-term. Another related possible discrepancy between TNTP's cost estimates and practitioners' experiences could be the fact that personnel supporting teachers might be, in reality, fewer than estimated (job titles v. roles and responsibilities). Finally, some costs might have been counted twice by the researchers (for ex. stipends and substitute teachers).

In terms of teachers' investment of time in professional development, this, too, seems high to a school-based educator. According to TNTP's survey, teachers dedicate approximately 150 hours per year ( $10 \%$ of a school year) on various types of PD.

Experiences from the field tell a different story. There is usually some type of teacher training at the beginning of each school year, conducted throughout 3 to 5 days, with sessions covering a variety of topics: school policies and procedures, operational and compliance issues, student and staff culture/safety, school opening procedures, and teaching and learning foci. Considering a 7-hour workday, the number of hours spent on professional development at the beginning of the school year could range from 21 to 35 hours, with a fraction actually spent on improving teaching practice.

For the rest of the school year, most districts have 2-3 PD days per semester when students are released for a half or full day so that teachers could participate in workshops or in-service programs that might be relevant to their professional development needs. Usually, district or school leaders select the topic "du jour" and all staff members are expected to attend sessions on the same topic. Some districts, however, offer a menu of topics and simultaneous sessions from which teachers could choose - so this approach might increase the chance that a teacher gets what she or he needs. While the PD facilitators are deemed "experts", there is little transparency as to how that expertise was earned. Teachers spend a couple of hours listening to a presentation, without the opportunity to truly engage and practice. If they are lucky, they might leave with some useful handouts and a few practical strategies. There is no follow up; there are no clear expectations of application, and accountability on teachers and their supervisors is usually not in place. Some of the sessions lack the research-based, evidence-based elements of effective professional development: PD should be informed by data (including from classroom observations, instructional rounds, student achievement results; etc.); training should be led effectivity, through air-tight activities and active engagement of participants; opportunities for practice, application, and reflection must be created; teachers and administrators should share the responsibility that the new skills and learning is genuinely implemented.

An exception to the time spent on development activities might be the teachers working in special education assignments. State and regional agencies usually provide additional funding that make more opportunities for training available to these educators.

Also, from experiences in the field: although some districts spend a considerable amount of moneyon professional development for teachers, the intended beneficiaries of these activities are sometimes not allowed to pick their own programs. Instead, school and district leadersselect professionaldevelopment products, topics, facilitators, and services.

Two clear ideas emerge from the observations above: a) reality shows that teachers' investment of time in their instructional practicedevelopment rarely reaches an average of 150 hours per teacher, per year, and b) the quality of professional development offered is very important to authentic growth (and relatively difficult to quantify). 
Nonetheless, the authors of The Mirage(TNTP, 2015) do make some claims related to districts' investment in teachers' development that resonate with educators in the field: a large investment in teacher improvement is both justified and advisable; offering a variety of developmental initiatives targeting instruction is smart; most school and district leaders have good intentions and display laudable commitment to support teachers; lack of customization to specific teacher needs is a cause of dissatisfaction for teachers; misaligned and uncoordinated efforts to train teachers work against the desired goal; and the "indifference" to analyzing PD's impact and making necessary adjustments is probably the main reason why teachers seem to be "marching in place" (p.13).

Key findings of the study related to results can be summarized in several sentences.

Most teachers in the districts examined seemed to be making relatively small progress year after year; when growth happened, it usually took place in the first few years of teaching, after which meaningful improvement stagnated. This last claim that the more significant improvement happens in the early years of teaching is supported by other research on the topic, reflects a natural learning curve for any personnew on the job, and is validated by observations from the field. Other findings refer to teachers reaching plateau before mastering core instructional practices and little differences between improvers and non-improvers in terms of time spent on developmental activities, level of satisfaction with the PD attended, or teachers' mindset. Teachers' self-perception about the effectiveness of their teaching practice does seem to correlate with their professional growth.TNTP's conclusion: "it's impossible to pinpoint a particular type, amount, or combination of development activities that is currently helping the average teacher improve more than any other" (p. 22) and "[s]ome teachers will get better, and about the same number won't" (p.22). The exception, again, are the teachers in the schools belonging to the CMO analyzed.

One aspect that render some of the findings questionable (especially to those working in schools) is the fact that the authors of the study relied on the correlationbetween professional development and growth in the teachers' ratings on their respective evaluation tool. As stated earlier in this article, teacher evaluation data is often inaccurate and unreliable.

\section{Review of Recommendations; Perspectives}

The authors of the study acknowledge that success of teacher development efforts is not contingent on "how much" districts spend. They recognize that "more" (professional development, coaches, mentors, money, time, etc.) is not necessarily better. They identify the lack of coordination among PD developers/providers and individualization of PD as contributing to the ineffectiveness of initiatives. And yet, in my opinion, they come short of using what they learned in this study to drive their recommendations.

Rather than recommending building on the initiatives, approaches, and strategies that work in the charter network in the study, the authors opine that we should "redefine what it means to help teachers improve" (p. 35), "reevaluate existing professional learning supports and programs" (p. 37), and "reinvent how we support effective teaching at scale" (p. 38). There is evident value in defining more clearly "teacher development" as "observable, measurable progress towards an ambitious standard for teaching and learning" (p. 35), evaluating the effectiveness of, and recalibrating current activities, programs, and supports, as necessary. There is also evidence in the study supporting these recommendations.However, the authors' last set of recommendations is unexpected, not supported by much in the study; and probably unattainable: reconstructing teacher's job and complementing investments in teacher development with equal investments in recruitment, added compensation for effective teachers, and "smart retention" (p. 38).

Teachers and school/district leaders would find some of the authors' recommendations very useful and practical. Redefine what it means to help teachers: making sure teachers uderstand the end goal of development activities, knowing one's standing related to instructional performance and progress, making teacher improvement a top priority, creating a sense of urgency around professional growth, developing clear metrics to track progress; aligning and creating synergy around all the PD support offered; and connecting improvement to authentic rewards and consequences - all these strategies are helpful in building a system of adult learning that is strategic, thoughtful, aligned to the school's instructional priorities, and maximizes the chance that the capacity of teachers and instructional leaders is improved over time.

Similarly, schools and school districts would alsogreatly benefit from a re-evaluation of what is currently happening in their organization. An examination of the programs and supports in place could uncover duplications, ineffective or misdirected initiatives. These could then be eliminated quickly. Structuring the teacher development efforts in a way that their impact can be measured and improving the quality of the districts' evaluation systems - including not only "true" multiple measures, but also tools, rubrics, protocols, norming of observers, quality of feedback; accountability systems, etc. -would be great steps to consider in starting the process of informing teachers' development needs based, 
in part, on the teaching effectiveness evaluation system. In addition, the authors' recommendation to reallocate funds for PD activities and initiatives based on their impact is wise, practical, and relatively easy to implement.

From an educator's point of view, at the opposite end of the spectrum of recommendations - in terms of feasibility, usefulness, and direct connection to the research conducted by TNTP for this study - is the idea of reinventing how effective teaching is supported at scale. The approaches recommended under investing more in recruiting teachers with a successful track record and "smart retention" (p. 38) strategies are certainly good ideas and somewhat doable, but the question that comes to mind is, "how do they address the problem of ineffective teacher development - which is the subject of this study"? Equally puzzling is the recommendation to reimagine (redesign) the teacher'sjob and the way we certify teachers for this profession. The idea that entry-level teachers could have a smaller workload and lessened responsibilities (such as just working with small groups of students, be responsible for grading students' work, or working with families only) until they build a "track record of success" (p. 38) is, at best, idealistic and, at worst, a logistics and financial nightmare. Same is true for the recommendation to reimagine the teacher certification and preparation programs. In this scenario, state regulators, universities, and school districts would radically change how teachers would be meeting certification requirements by designing a new system of progressive licensure.

At the core of teacher training, the authors recommend a comprehensive and lengthy apprenticeship program, with candidates having the opportunity to practice and master different competencies and skills in a staggered way, while being "on the job", and paid by school districts. While this innovative idea is laudable and has some merits, the process leading to this type of change would be extremely lengthy, its implementation very costly and, overall, the approach would be impractical - for ex., the involvement of state, universities, and districts would require massive coordination efforts and probably too much negotiation at the expense of true change.

\section{Conclusions}

Bringing out the best in each teacher through professional development initiatives is a hefty and humbling goal. A lot can be learned from this study. If we take the new learnings about what NOT to do, along with the vision, culture, successful practices and systems from the CMO in the study; and if we combine all this with knowledge from other research on designing and leading effective professional development; and, lastly, if we keep the dialogue open with the people in the field, and learn from teachers, school and district leaders, PD experts, etc. - we will then be in a much better position to build a systematic, effective approach to train and support all of our teachers in a way that would translate to increased student learning. The myth of the professional development being a mirage will be then dispelled.

\section{References}

No Child Left Behind Act of 2001, P.L. 107-110, 20 U.S.C. § 6319 (2002).

TNTP (2015). The mirage: Confronting the hard truth about our quest for teacher development. Washington, DC: Authors.

Belcher, K. (2015). The Five Stages of the Mirage. TNTP blog. Retrieved from https://tntp.org/blog/post/the-fivestages-of-the-mirage.

Bennett, C. (2020). Contrasting Growth and Proficiency Models for Student Achievement. Retrieved from https://www.thoughtco.com/growth-model-vs-proficiency-model-4126775.

Bornfreund, L.A. (2013). An ocean of unknowns: Risks and opportunities in using student achievement data to evaluate preK-3rd grade teachers. Washington, DC: New America Foundation.

Coe, R., Aloisi, C., Higgins, S.,\& Major, L.E. (2014). What makes great teaching? Review of the underpinning research, Project Report. Sutton Trust: London.

Darling-Hammond, L. \&Youngs, P. (2002). Defining "Highly Qualified Teachers": What Does "Scientifically-Based Research" Actually Tell Us?Educational Researcher, 31(9),13-25.http://www.jstor.org/stable/3594491.

Goddard, R.D., Hoy, W.K. and Woolfolk Hoy, A. (2000) Collective Efficacy: Its Meaning, Measure, and Impact on Student Achievement. American Educational Research Journal, 37, 479-507. http://dx.doi.org/10.3102/00028312037002479.

Grossman, P., Cohen, J., Ronfeldt, M., \& Brown, L. (2014). The Test Matters: The Relationship Between Classroom Observation Scores and Teacher Value Added on Multiple Types of Assessment. Educational Researcher, 43(6). 293-303.

Hamilton, L., Halverson, R., Jackson, S. S., Mandinach, E., Supovitz, J. A., Wayman, J. C., Pickens, C., Martin, E., \& Steele, J. L. (2009). Using Student Achievement Data to Support Instructional Decision Making. United States Department of Education. Retrieved from https://repository.upenn.edu/gse_pubs/279.

Hill, C. H. (2015). Review of The Mirage: Confronting the Hard Truth About Our Quest for Teacher Development. Boulder, CO: National Education Policy Center. Retrieved from 
https://nepc.colorado.edu/sites/default/files/ttr_hill_tntp_mirage.pdf

Jacob, A., Vidyarthi, E., Carroll, K. (2012). The Irreplaceables. Understanding the Real Retention Crisis in America's Urban Schools. Rep. Brooklyn: TNTP

Lachlan-Haché, L., \& Castro, M. (2015). Proficiency or Growth? An Exploration of Two Approaches for Writing Student Learning Targets. Performance Management Advantage Evaluation \& Professional Growth at American Institutes for Research.

Newton, X. A., Darling-Hammond, L., Haertel, E., \& Thomas, E. (2010). Value-Added Modeling of Teacher Effectiveness: An Exploration of Stability across Models and Contexts. Education PolicyAnalysis Archives, $18(23), \mathrm{n} 23$.

U.S. Department of Education (2009). Race to The Top program executive summary. Washington, D.C.: U.S. Department of Education. Retrieved from http://www2.ed.gov/programs/racetothetop/executive-summary.pdf

Weisberg, D., Sexton, S., Mulhern, J., \& Keeling, D. (2009). The widget effect: Our national failure to acknowledge and act on differences in teacher effectiveness. Washington, D.C.: The New Teacher Project. 